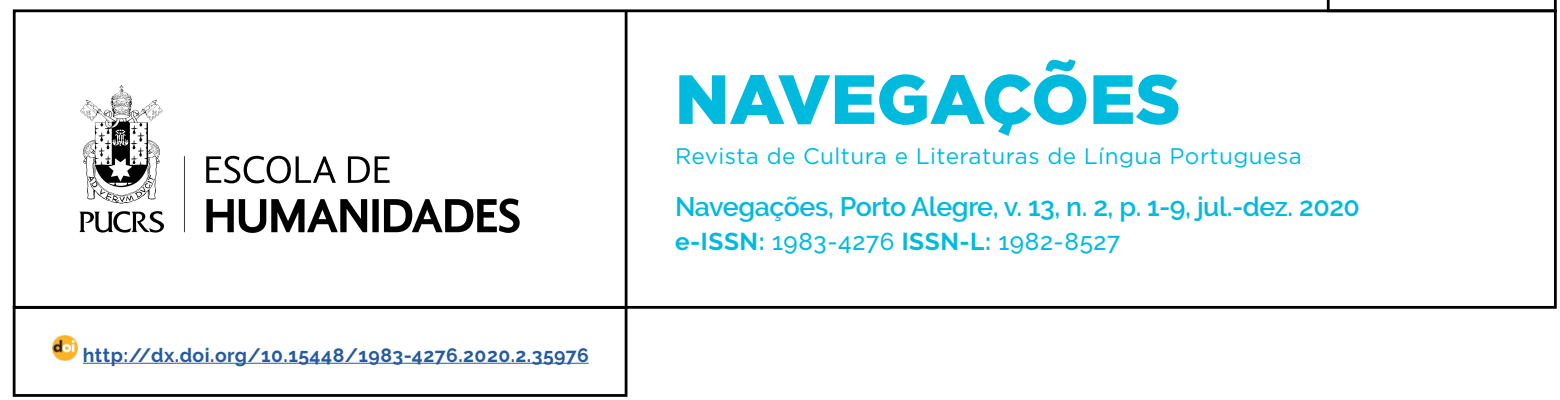

SEÇÃO: ENSAIOS

\title{
A memória do Holocausto em Uma menina está perdida no seu século à procura do pai, de Gonçalo M. Tavares
}

The Holocaust memory in Uma menina está perdida no seu século à procura do pai, with Gonçalo M. Tavares

\section{Leonardo von Pfeil}

Rommel $^{1}$

orcid.org/0000-0001-6312-1887

lvpfeil@hotmail.com

Recebido em: 15/10/2019

Aprovado em: 27/4/2020.

Publicado em: 25/2/2021.

\section{(c) (1)}

Artigo está licenciado sob forma de uma licença Creative Commons Atribuição 4.0 Internacional.
Resumo: O presente ensaio analisa a representação da memória do Holocausto no romance Uma menina está perdida no seu século à procura do pai, de autoria do escritor português Gonçalo M. Tavares. Publicado em 2014, cerca de 70 anos após o final da Segunda Guerra Mundial, evento responsável por marcar profundamente o século XX, a narrativa é ambientada em um cenário pós-guerra, revisitando, assim, as consequências traumáticas de uma das maiores catástrofes da história da humanidade. O romance de Gonçalo $M$. Tavares aponta para a necessidade de não esquecimento dos traumas do passado. A literatura assume-se como um discurso de memória, dotada de um compromisso ético e político.

Palavras-chave: Holocausto. Memória. Trauma. Humanismo. Gonçalo M. Tavares.

Abstract: The present essay analyzes the representation of Holocaust memory in the novel Uma menina está perdida em seu século à procura do pai, authored by portuguese writer Gonçalo M. Tavares. Published in 2014, some 70 years after the end of World War II, an event that deeply marks the twentieth century, the narrative is set in a postwar scenario, revisiting the traumatic consequences of one of the greatest disasters in history of humanity. Gonçalo M. Tavares's novel points to the need to not forget the traumas of the past. Literature is assumed as a memory discourse, endowed with an ethical and political commitment,

Keywords: Holocaust. Memory. Trauma. Humanism. Gonçalo M. Tavares.

O século XX, de acordo com a visão de Eric Hobsbawn (1995), pode ser definido como a Era dos Extremos, uma vez que as duas guerras mundiais, o extermínio em massa de seres humanos durante o Holocausto, perpetrado pela ideologia nazista, e a utilização da tecnologia a serviço da devastação, transformaram o século no período mais violento da história da humanidade. A Segunda Guerra Mundial tornou-se paradigmática, tendo-se em vista que os campos de concentração e a detonação das duas bombas atômicas em Hiroshima e Nagasaki soaram como um prenúncio do apocalipse, uma vez que o homem provou ser capaz de deter os meios de erradicar a espécie humana e devastar o planeta por completo.

A Segunda Guerra Mundial foi uma guerra total, evento responsável pela liberação de violência extrema, uma vez que mobilizou praticamente todos os paises do globo terrestre e reduziu muitas cidades a pó por meio dos pesados bombardeios. Na Europa Ocidental, como aponta Tony Judt (2008, p. 18-19), a "Wehrmacht riscou do mapa muitos vilarejos na rota de invasão através da Polônia e, mais tarde, também 
da lugoslávia e da União Soviética", tendo ainda arrasado Roterdã e Coventry, importante polo industrial inglês. Quando a guerra já se aproximava do final, os aliados norte-americanos e ingleses destruíram o Sul da França e o Exército Vermelho, avançando a partir do Leste, deixou um rastro de destruição até alcançar Berlim, transformando, assim, a Europa em uma terra arrasada.

Na sequência da Segunda Guerra Mundial, a perspectiva da Europa era de miséria e desolação total. Fotografias e documentários da época mostram fluxos patéticos de civis impotentes atravessando paisagens arrasadas, com cidades destruidas e campos áridos. [...] Crianças órfãs perambulam melancólicas, passando por grupos de mulheres exaustas que reviram montes de entulho. Deportados e prisioneiros de campos de concentração, com as cabeças raspadas e vestindo pijamas listrados, fitam a câmera, com indiferença, famintos e doentes. Até os bondes parecem traumatizados - impulsionados por corrente elétrica intermitente, aos trancos, ao longo de trilhos danificados. Tudo e todos [...] parecem surrados, desprovidos de recursos, exauridos (JUDT, 2008, p. 15).

Os principais danos causados pela guerra se deram na existência humana. Os campos de concentração, espaços onde milhões de vidas inocentes foram interrompidas, ficaram marcados na história da humanidade como a materialização da barbárie total. O Holocausto pode ser visto como o evento-limite, como a catástrofe por excelência, evento que fragmentou as barreiras da realidade, responsável pela degradação total da humanidade, uma vez que a vida humana foi reduzida a números, tudo isso como consequência da loucura política, do ódio e do desejo de poder.

O processo de eliminação do povo judeu, por parte da Alemanha nazista, através dos campos de extermínio, foi estrategicamente concebido com a intenção de apagar todo e qualquer vestígio de humanidade das vítimas. De acordo com Roney Cytrynowicz (2003, p. 125), durante seu auge, entre os anos de 1941 e 1945, "o processo de genocidio dos judeus europeus foi concebido e executado [...] para evitar qualquer reação das vitimas", negando-as até mesmo a consciência de que estavam sendo assassinadas. Ainda segundo o autor, nos campos de concentração "o genocidio atingiu uma escala industrial, organizada em termos de custo-benefício" (CYTRINOWICZ, 2003, p. 125), algo sem paralelos na história da humanidade.

O sistema de extermínio alemão produziu aquilo que Hannah Arendt definiu como a banalidade do mal, uma vez que com a utilização das câmaras de gás "atingiu-se o limite máximo da capacidade física de matar com o máximo de não envolvimento pessoal dos próprios nazistas" (CYTRYNOWICZ, 2003, p. 126). Através da técnica e da ciência, a brutalidade nazista foi levada ao absurdo, uma vez que médicos eram responsáveis pelo gerenciamento e supervisão de todo o processo de seleção na entrada dos campos, além de operarem as câmaras de gás e conduzirem inúmeros experimentos macabros utilizando-se dos presos.

O Holocausto marca uma ruptura na história da humanidade. Nada depois de Auschwitz permaneceu igual, não deve e não poderia permanecer igual. O regime nazista demonstrou para o mundo a profundeza da maldade que um homem é capaz de infligir a outro homem. De acordo com Jeanne Marie Gagnebin (2003, p. 104), após a Segunda Guerra Mundial "a mais nobre característica do homem, sua razão e sua linguagem, o logos, não pode [...] permanecer a mesma, intacta em sua esplêndida autonomia" uma vez que "a aniquilação de corpos humanos nessa sua dimensão originária [...] contamina a dimensão espiritual e intelectual [...]," destruindo assim, a soberania da razão humanista. Ainda de acordo com Gagnebin (2003), a ruptura causada pelo Holocausto deixou marcas profundas também na arte e na linguagem, que adquirem o compromisso ético de resgatar o passado traumático.

No dominio mais especificamente estético, esse abalo da razão e da linguagem tem consequências drásticas para a produção artística. Criar em arte - como também em pensamento - "após Auschwitz" significa não só rememorar os mortos e lutar contra o esquecimento, uma tarefa por certo imprescindivel, mas comum à toda tradição desde a poesia épica, mas também acolher, no próprio movimento de rememoração, essa presença do sofrimento sem palavras, nem conceitos, que desarticula a vontade de coerência e de sentido de nossos empreendimentos artísticos e reflexivos (GAGNEBIN, 2003, p. 104). 
De acordo com George Steiner (1988, p. 12), a violência irradiada pelo nazismo, pela bomba atômica e pelos campos de concentração danificou a linguagem humana, afetou a indole humanista desta "estrutura de fantástica complexidade e vulnerabilidade; [que] provavelmente define a humanidade do homem". A lógica dos campos de extermínio, com sua burocracia, seus milhares de oficios, ordens e trâmites criou uma novilingua (CYTRYNOWICZ, 2003), responsável por impedir qualquer referência à morte, mesmo que na realidade a morte estivesse sendo executada de maneira bárbara e covarde. A mentira, o cinismo, a violência e a absurda desintegração do homem, em sua vertente física e existencial, atingem em cheio as formas de expressão e de pensamento.

Após a destruidora experiência do Holocausto, a literatura assume um papel social de suma relevância ao resgatar a linguagem, questionar o passado e apresentar denúncia sobre um presente em que as dúvidas e as incertezas desorientam o ser humano em sua essência. De acordo com Seligmann-Silva (2003, p. 12), "toda obra de arte, em suma, pode e deve ser lida como um testemunho da barbárie", como mecanismo de desconstrução e de enfrentamento da opressão, como alternativa de memória e de libertação da condição humana através da subjetividade.

A questão da importância da literatura e da arte enquanto possibilidade de testemunho e de representação das catástrofes e das barbáries após o Holocausto é problematizada por Theodor Adorno em seu ensaio Crítica Cultural e sociedade, publicado em 1949, onde, após a aniquilação profunda da existência humana pela técnica nos campos de concentração nazistas, o autor apresenta o posicionamento de que "escrever um poema após Auschwitz é um ato bárbaro, e isso corrói até mesmo o conhecimento de por que hoje se tornou impossivel escrever poemas" (ADORNO, 1998, p. 26.).

O apontamento de Adorno chama atenção para o fato de que a arte, ao abordar catástrofes, se encontra frente a um paradigma, uma vez que ela tenta suprir a realidade, narrar o inenarrável, ou seja, tenta simbolizar e transformar em linguagem a violência extrema e a morte, mas essa é uma tarefa eticamente impossivel, já que jamais se pode nominar integralmente o sofrimento, a dor e a perda humana. Em relação ao Holocausto, esse paradigma se expande, uma vez que a apresentação realística dos fatos muitas vezes soava como irreal, tendo assim seu efeito diluído.

Os primeiros documentários e fotografias que apresentavam a realidade dos campos imediatamente após a chegada das tropas aliadas não raramente despertavam nos espectadores a incredulidade frente às montanhas de corpos e a toda uma estrutura cientificamente elaborada para promover o extermínio de vidas humanas em escala industrial. Na visão de Seligmann-Silva (2003, p. 95. grifo do autor), "devido ao elemento inacreditável de hiper realidade do campo de concentração a narração deve lançar mão da arte", para que assim se evite um efeito de dessensibilização da sociedade. Nesse sentido, o papel da arte e da literatura ganha relevância como alternativa de memória ao reorganizar a realidade, abordando-a através de símbolos e possibilitando assim a abertura de um "espaço para o jogo mutuamente fecundante entre a imaginação e a reflexão" (SELIGMANN-SILVA, 2003, p. 94) sobre a realidade marcada pela presença disruptiva da barbárie.

No romance Uma menina está perdida no seu século à procura do pai, publicado em 2014, às vésperas dos 70 anos do final da Segunda Guerra Mundial, o escritor português Gonçalo M. Tavares, por meio do discurso literário, procura forçar a abertura de um jogo dialógico de reflexão entre o passado histórico, marcado profundamente pelos traumas dos campos de concentração e pela devastação da Europa, com a contemporaneidade, almejando, assim, a construção de uma memória histórica do Holocausto.

Gonçalo M. Tavares destaca-se na literatura portuguesa contemporânea ${ }^{2}$ como um dos escri- 
tores mais plurais e enigmáticos de sua geração. Sua produção ficcional, vasta e hibrida, contempla diversos gêneros literários e discursivos, como teatro, poesia, romance e ensaio. Tendo-se em vista a grande fluidez e a heterogeneidade estética de suas obras, segundo o próprio autor, há "imensos caminhos para fazer literatura" (MARINHO, [2016])3, e "Eu gosto de muitas coisas, filosofia, ciência ou matemática e não distingo, por exemplo, o ensaio da narrativa, acho que são o mesmo mundo. A narrativa pode pensar, um ensaio também" (MARINHO, [2016]).

A presença do Holocausto, de acordo com o próprio escritor, é marcante em sua obra, uma vez que, segundo suas palavras, "Muitos dos meus livros têm como paisagens o Século XX e de alguma forma o holocausto" (MARINHO, [2016]). Tal evento histórico é abordado com maior ênfase na série "O Reino", composta por quatro romances, Um Homem: Klaus Klump (2003), A Máquina de Joseph Walser (2004), Jerusalém (2005) e Aprender a Rezar na Era da Técnica (2007), todos denominados pelo próprio autor como os livros pretos, narrativas onde o autor explora as ambiguidades existentes no comportamento e na existência humana, como a tênue fronteira que separa a razão da loucura, e a perenidade dos conceitos de bem e mal, além de lançar reflexões sobre o caráter sombrio e absurdo do pensamento lógico e da técnica quando associados à produção da violência.

O romance em análise. Uma menina está perdida no seu século à procura do pai, é dividido em 15 capítulos contendo, ao todo, 48 partes, micronarrativas. Cada micronarrativa vai apresentando um determinado acontecimento e, gradualmente, vai se encaixando às passagens anteriores e às seguintes, formando, assim, o desenvolvimento e a unidade da intriga do romance. A heterogeneidade estrutural da narrativa, que subverte a lógica dos relatos tradicionais, apresenta-se como estilo próprio de Gonçalo M. Tavares que, ao lançar mão de um estilo de texto concentrado em pequenos blocos, potencializa o "pendor ensaístico nos romances, concretizado em discursos sentenciosos, próprios das chamadas formas gnómicas" (PETROV, 2011, p. 130), onde narradores e personagens exploram questões de ordem filosófica, muitas vezes, através de metáforas, máximas e aforismos.

Tendo-se em vista que os romances de Gonçalo M. Tavares trabalham constantemente com a representação da violência, do trauma e da opressão, seu estilo literário absorve o sofrimento humano na materialidade híbrida e fragmentária dos seus textos. O trauma e a barbárie perpassam as letras e as linhas de suas narrativas. De acordo com Jaime Ginzburg (2000, p. 50), nas obras literárias que buscam representar as catástrofes históricas, como o Holocausto, a fim de evitar o processo de banalização da realidade, e poder abrir um espaço de reflexão, muitas vezes "encontramos lapsos, descontinuidades, contradições, subversões de convenções, rupturas com gêneros tradicionais, questionamentos a respeito da capacidade comunicativa e expressiva da literatura". Essa experimentação formal e estética encontrada na obra do escritor português, direta ou indiretamente diz respeito ao impacto das catástrofes históricas na vida de todos nós.

Em Uma menina está perdida no seu século à procura do pai temos dois protagonistas: a personagem central é Hanna, uma adolescente de 14 anos, portadora de uma síndrome genética, $a$ trissomia 21, popularmente conhecida como Síndrome de Down. A garota traz consigo uma caixa contendo uma série de fichas, uma espécie de curso ou manual com os passos para guiar sua comunicação com outras pessoas e o seu processo de desenvolvimento mental, psicomotor e social.

O segundo protagonista é Marius, um homem de caráter sombrio e misterioso que demonstra ser assombrado por acontecimentos de seu passado, uma vez que manifesta sentir "[...] uma dor não física, um claro incômodo; dor, portanto, mas não localizável [...]" (TAVARES, 2015, p. 15). Seus segredos o obrigam a manter-se sempre

3 MARINHO, Raquel. Escrever tem de ser organicamente indispensável. Expresso. Lisboa, 10 fev. 2016. Disponivel em: https://expresso. $\mathrm{pt} /$ cultura/2016-02-10-Escrever-tem-de-ser-organicamenteindispensavel?utm_source=site\&utm_medium=share\&utm_campaign=facebook\&fbclid=IwAROO2Bas-88NAOh4m1ZR52p40YqYUjJmLMFjr91-L3XqghlHjUJEJPZklj4. Acesso em: 14 jun. 2020. 
em fuga, em estado de vigilância, uma vez que ele busca sempre "esconder-se o mais possivel, estar atento às notícias, ir ouvindo a rádio, perceber se precisa de mudar de cidade, se a sua fuga tem de ser óbvia, se é necessário correr [...]" (TAVARES, 2015, p. 86).

Sua trajetória de constante movimentação e de fuga é interrompida ao encontrar Hanna, abandonada e indefesa, vagando sem destino. Ao analisar as fichas em posse da menina, ele consegue descobrir que ela estava perdida e que procurava pelo pai. O nome do pai é desconhecido, uma vez que Hanna é impedida de revelar seu nome por ter sido ameaçada de morte caso o fizesse. Assim estabelece-se a união dos personagens que passam a andar juntos em busca de respostas e das origens de Hanna.

A narrativa se desenvolve em um periodo pós-guerra, ao que tudo indica, na Alemanha, uma vez que ao ser questionada por Marius sobre onde poderiam encontrar o seu pai, a resposta de Hanna aponta para Berlim, mas essa coordenada geográfica é informada sob um tom de incerteza: "- Onde podemos procurar o teu pai?/ - Blim - respondeu Hanna./ - O teu pai está em Berlim? É de Berlim?/ - Belim - respondeu Hanna" (TAVARES, 2015, p. 26). O fato de Hanna estar perdida e vagando pela cidade liga-se também à situação da Alemanha pós-guerra, uma vez que a maioria das cidades haviam sido completamente destruidas pelos bombardeios dos aliados e pelo avanço terrestre do Exército Vermelho. A guerra reduziu as cidades a espaços devastados onde montanhas de concreto e de aço ardiam em chamas e onde dezenas de milhares de crianças estavam perdidas, órfãs ou abandonadas.

Os dois protagonistas tomam um trem e se dirigem à capital do país. Nessa jornada de busca, encontram-se com várias pessoas diferentes, todos, assim como eles, sujeitos errantes. Muitos dos encontros desencadeiam diálogos e situações absurdas, insólitas e que beiram o grotesco, algo já marcante na ficção de Gonçalo M. Tavares. Todos os encontros geram uma pequena intriga que vai gradualmente construindo a ideia central do romance: a necessidade de conhecimento do passado e a valorização da memória. A viagem de Hanna e Marius em busca do pai da garota obriga-os, a eles, personagens, e também ao leitor, a um processo de aprendizagem e de reflexão sobre a importância da memória, elemento essencial da identidade humana e, também, sobre o afeto e os traumas do passado.

Após a chegada à cidade de Berlim, por indicação de um homem que conheceram durante a viagem de trem, encaminham-se para um pequeno hotel, localizado em uma zona degradada da cidade. A chegada ao hotel trata-se do ponto central da narrativa, uma vez que neste espaço Hanna e Marius deparam-se com a memória do Holocausto, herança traumática da história do povo judeu e da humanidade como um todo. $O$ hotel não possui nome e é administrado por um casal de judeus, Raffaela e Moebius. No prédio, os quartos não possuem números, são identificados através do nome dos campos de concentração criados pela Alemanha nazista, fato esse, no mínimo grotesco e que gera desconforto em Marius.

A senhora pôs a chave em cima do balcão. Uma chave normal a que estava presa uma pequena tábua de madeira com um nome. Fixei os olhos no nome do quarto.

- Os quartos não têm número? - perguntei.

- Só têm nome. O hotel é pequeno, é fácil chegar lá. É depois deste longo corredor. Encontra rapidamente o quarto.

Olhei de novo para a placa de madeira. Não havia qualquer dúvida. O que estava escrito na placa de madeira era AUSCHWITZ.

- Este é o nome do quarto?

- Sim - respondeu ela.

- Não tem outro quarto?

- Temos outro vago. E com duas camas. Mas se é a questão do nome não adianta muito.

E afastou-se para eu poder ver atrás dela o mapa dos quartos. Todos tinham o nome de um campo de concentração: TREBLINKA, DACHAU, MAUTHAUSEN-GUSEN

Marius pensou em várias coisas ao mesmo tempo. Teve o impulso de virar as costas de imediato e de tirar Hanna dali, mas não o fez.

- Por que fazem isso?

- Porque podemos - respondeu a senhora, secamente. - Somos judeus (TAVARES, 2015, p. 52-53). 
Ao amanhecer do dia seguinte, Hanna e Marius partem à procura de pistas sobre a origem da menina e sobre o paradeiro do pai. Um objeto metálico que Hanna portava ao ser encontrada leva os dois a um decrépito antiquário da cidade, onde conhecem Vitrius, dono do estabelecimento e portador de uma curiosa tarefa herdada de seus antepassados: preencher uma lista com uma sequência interminável de números pares. "- Foi o meu bisavô que começou isto. Tornou-se uma tradição de família. Passou para o meu avô, depois para o meu pai, agora para mim. [...] - Em parte é a minha salvação, disse Vitrius a rir-se [...]" (TAVARES, 2015, p. 103). Ainda questionado por Marius sobre a necessidade e a utilidade de escrever os números, Vitrius arremata: "Trata-se de resistir" (TAVARES, 2015, p. 107).

Para Vitrius, o interminável exercício de escrita e arquivamento dos números, o exercício de memória, assume uma dimensão existencial, "um trabalho religioso" (TAVARES, 2015, p. 109), que garante a sua sobrevivência. Para o velho negociante de objetos sem uso, preservar a memória e as tradições do passado trata-se de uma forma de existência e de resistência, uma vez que, ainda segundo ele, a tarefa de preservar o passado foi uma alternativa encontrada por seus antepassados para superar as barbáries do século XX. Registrar os números, deixar rastros escritos que remetam ao passado, foi uma forma de "sair do século, e de sair de uma forma concreta [...], calmamente, com elegância, sem sofreguidão, abrindo uma porta e fechando-a, depois, quase sem ruido" (TAVARES, 2015, p. 109).

E foi a melhor das protecções que o meu avô e o meu pai tiveram - acho que sobreviveram ao mundo por causa disto. Por vezes penso mesmo que uma bomba ou um tiro, dos muitos que andaram por ai nas diferentes épocas, não lhes acertaram porque eles estavam concentrados nisto, neste trabalho (TAVARES, 2015, p. 109).

Rememorar a história e a origem do povo judeu: eis o principal compromisso de vários dos personagens do romance. Moebius, dono do hotel, possui as costas inteiramente preenchidas por tatuagens da palavra Judeu, escrita nas mais diversas línguas do planeta, tornando-se, assim, uma espécie de "dicionário em todas as línguas do mundo, mas dicionário de um único vocábulo. Dicionário que era ainda, simultaneamente, um mapa anatômico e geográfico" (TAVARES, 2015. p. 137). As inscrições começaram, como o próprio Moebius explica, "por uma espécie de orgulho de raça" (TAVARES, 2015, p. 137), após um periodo de perseguição aos judeus de sua cidade.

A palavra Judeu tatuada em seu corpo atua como um signo, um rastro que fala de suas origens e de sua identidade. Os traços desenhados em seu corpo guardam ainda uma ideia de transcendência frente à morte e à passagem do tempo, uma vez que, segundo Moebius, o quê em suas costas encontra-se escrito, "nem depois de morrer [...] vai sair" (TAVARES, 2015, p. 135). O corpo de Moebius atua como suporte, arquivo, e "resume perfeitamente a dialética da memória e da identidade que se conjugam, se nutrem mutuamente, se apoiam uma na outra para produzir uma trajetória de vida, uma história, um mito, uma narrativa" (CANDAU, 2018, p. 16).

Moebius demonstra uma espécie de obsessão com a necessidade de rememorar e manter vivas as suas origens e a história de seu povo. Revela ainda a Marius uma curiosidade sobre a estrutura de seu hotel: a planta baseia-se em uma figura geométrica obtida a partir do traçado do posicionamento geográfico dos vários campos de concentração. A posição de cada quarto corresponde diretamente à posição do respectivo campo no mapa.

\begin{abstract}
A planta do hotel era, mais milimetro, menos milimetro, uma cópia da estrutura geométrica formada pelos pontos que no mapa assinalavam os campos. E exactamente na mesma posição relativa de cada campo estava o quarto com o mesmo nome. Percebi finalmente a organização dos quartos. [...] - a relação era uma relação geográfica: o quarto de nome Arbeitsdorf estava entre Bergen-Belsen e Ravensbruck, um pouco metido para dentro, tal como se podia ver no mapa dos Campos. O hotel era reduzido, é certo, minúsculo, uma miniatura, mas era, em termos proporcionais, a cópia exacta da geografia dos campos de concentração (TAVARES, 2015, p. 94).
\end{abstract}

O traçado geográfico dos campos de concentração revela, segundo Moebius, "uma forma geométrica negra" (TAVARES, 2015, p. 95), uma 
figura inominável, que "não é um quadrado, nem uma circunferência, enfim, não é nenhuma forma geométrica reconhecivel [...]" (TAVARES, 2015, p. 95). Ainda, como explica Moebius, a impossibilidade de nomear corretamente ou caracterizar tal forma geométrica, "não é razão para ficarmos mudos [...]" (TAVARES, 2015, p. 95). A figura sombria desenhada por Moebius trata-se de uma forma de simbolizar o horror e a barbárie dos campos de concentração nazistas. Para falar do trauma, do massacre do povo judeu, Moebius utiliza um signo, um rastro. Se é impossivel nomear ou revelar o nome dessa forma geométrica, é porque trata-se de tarefa impossivel representar ou falar exemplarmente sobre o Holocausto.

Diante do esvaziamento da linguagem e das formas de expressão promovidas pela barbárie do Holocausto e pelos traumas da Segunda Guerra Mundial, as formas tradicionais de representação e de legibilidade são ultrapassadas pelo impacto doloroso da realidade. Dessa forma, o sujeito que testemunha esse periodo sombrio da história humana, muitas vezes, lança mão da escrita de signos, metáforas e rastros como forma de enfrentar a intraduzibilidade dos eventos.

Como aponta Jeanne Marie Gagnebin (2002, p. 128), a escrita pode ser "considerada como sendo o rastro mais duradouro que possa deixar um homem, uma marca capaz de sobreviver à morte de seu autor e de transmitir sua mensagem". Percebe-se desse modo que, tanto para Moebius, como para Vitrius, a escrita desempenha papel central no processo de conservação e de transmissão da memória histórica. Enquanto Vitrius utiliza-se de números, signos, Moebius utiliza a palavra e a figura geométrica; ambas as formas de escrita e de representação atuam como uma metáfora da memória do Holocausto.

Durante sua estadia no hotel, Hanna e Marius conhecem um antigo hóspede, o velho Terezin, que também carrega consigo a necessidade de manter viva a memória do passado e, assim como eles, andava ainda em busca de suas origens. 0 velho guia Hanna e Marius até um prédio em ruínas, completamente esquecido e abandonado. O edificio era "um dos antigos arquivos da cidade" (TAVARES,
2015. p. 172) e Terezin costumava visitar os escombros regularmente pois, em meio a fichas e arquivos destruidos e consumidos pela passagem do tempo, segundo ele, "-Investigava [...] a minha familia, as minhas origens" (TAVARES, 2015, p. 175-176).

Em um muro lateral à estrutura, eles encontram grafada a pauta de uma música familiar a Terezin: "- Foi esta música - disse, de súbito Terezin - que eu assobiei interminavelmente quando estive preso. É de uma grande utilidade, a música acrescentou, de uma forma seca" (TAVARES, 2015, p. 176). Diante dos arquivos danificados, resta a Terezin a memória de uma canção, metáfora de que, diante do apagamento e da destruição de materiais físicos, a memória e a arte resistem, surgem como alternativas de resgate do passado.

O velho Terezin contou então que eles, os judeus, não confiavam em documentos, em papéis, em fotografias, em suma, em nenhum registo concreto, material, palpável.

- Viu aquele arquivo?

E como não confiavam no que se poderá chamar de matéria por mais moderna que fosse a técnica e a segurança que transmite a sua conservação, e as sucessivas promessas de imortalidade - haviam regressado, de certa maneira ao passado, e decidido conservar na memória humana o que teria mesmo de ser defendido, o que nunca deveria ser engolido por qualquer vandalismo - ou dos homens ou dos elementos naturais (TAVARES, 2015, p. 185-186).

Um dos principais objetivos dos campos de concentração era apagar todo e qualquer vestígio da existência do povo judeu e dos assassinatos ali perpetrados pela Alemanha nazista. De acordo com Hannah Arendt (1991, p. 241), diante da derrota iminente, "durante as últimas semanas da guerra, a burocracia da SS ficou ocupada principalmente com a falsificação de documentos e com a destruição de montanhas de papel que atestavam seus anos de assassinato sistemático". Milhares de corpos de prisioneiros que haviam sido jogados em valas comuns foram desenterrados para que fossem queimados, evitando, desse modo, que restasse qualquer rastro ou sinal dos crimes.

Terezin, judeu e, ao que tudo indica, um antigo prisioneiro do campo, sabe dessa lógica e, portanto, não confia nos documentos, sabe que a História pode ser apagada, falseada e violentada pelo 
Homem, uma vez que, segundo ele, "I...] qualquer pessoa lúcida já percebeu que apesar de tudo, é mais fácil eliminar os arquivos materiais de um determinado grupo humano do que a totalidade dos seus elementos" (TAVARES, 2015, p. 190).

Ainda de acordo com Terezin, a questão da memória se tornou fundamental para os judeus, tanto que "havia, espalhados pelo mundo, sete homens, sete judeus, que tinham memorizado, sem qualquer falha, toda a História do século XX" (TAVARES, 2015, p. 186). Esses homens são conhecidos como homens-memória, cuja tarefa primordial consistia em não esquecer e passar adiante seus conhecimentos. Como aponta ainda Terezin, "os sete Séculos XX [...] eram os novos guardiães de um novo texto sagrado" (TAVARES, 2015, p. 188-189, grifo do autor), a história do século XX e a memória do Holocausto.

Memorizaram, como deve calcular, todos os dados, até ao mais pequeno pormenor, sobre o que aconteceu nos campos de concentração. Os sete 'Séculos XX' memorizaram a planta dos Campos - são capazes de os desenhar em qualquer altura; memorizaram a localização e as medidas das celas, memorizaram o número de mortos por cidade, por ano e mês, memorizaram os nomes das famílias que desapareceram nesses anos, memorizaram o que alguns sobreviventes relataram por escrito e memorizaram pormenores sórdidos, que escuso de the descrever (TAVARES, 2015, p. 186).

A fim de que a história do século XX e as atrocidades praticadas pelo nazismo contra o povo judeu jamais sejam apagadas ou esquecidas, os Sete Séculos XX utilizam-se da memória e da narrativa oral como forma de registrar e de transmitir suas experiências. Os judeus, dessa forma, buscam combater a pobreza da experiência, aquela "nova forma de miséria lque] surgiu com esse monstruoso desenvolvimento da técnica, sobrepondo-se ao homem", que fora diagnosticada por Walter Benjamin (1987, p. 115) ainda nas primeiras décadas do século $X X$, após a destruidora experiência da Primeira Guerra Mundial e da ascensão do nazismo na Alemanha.

É por meio da existência e da narrativa destes homens-memória que, segundo Terezin, "[...] teremos a certeza de que, se todas as fotografias e imagens desaparecerem, se todos os docu- mentos forem destruídos por uma calamidade qualquer ou por vontade de alguém [...]" (TAVARES, 2015, p. 190), em vários pontos do mundo "[...] existirão ainda judeus a contar a mesma história, a relembrar os factos, os dados - e sem falhas, todos com o mesmo discurso, exactamente com as mesmas palavras [...]" (TAVARES, 2015, p. 190), garantindo, assim, a transmissão da memória do Holocausto e da identidade do povo judeu.

Ao analisar-se a postura dos personagens Vitrius, Moebius e Terezin quanto ao seu trabalho de resgate e de transmissão da memória do Holocausto e do povo judeu, percebe-se que sua luta é travada contra o esquecimento, uma vez que, "não satisfazer o dever de memória é expor-se ao risco do desaparecimento" (CANDAU, 2018, p. 126). Através de seu trabalho de memória, os três personagens almejam conservar a identidade do povo judeu e reatar os elos identitários, individuais e coletivos, fragmentados pela violência e pela opressão. O ato de relembrar as barbáries e os crimes do passado trata-se, assim, de uma tarefa altamente ética e política, que cumpre também com um dever terapêutico, uma vez que as memórias "ajudam a enterrar os mortos do passado e a cavar um túmulo para aqueles que dele foram privados" (GAGNEBIN, 2006, p. 47).

Ao final do romance, Hanna não encontra seu pai, e a jornada à procura de suas origens fica em aberto, porém, ao partirem em uma busca por respostas individuais, ela e Marius deparam-se com a história da humanidade no século $X X$, a Era dos extremos. Durante sua jornada de bus$\mathrm{ca}$, ambos os protagonistas seguem os rastros deixados pela barbárie do Holocausto e, dessa forma, atuam com tradutores, pois, junto ao leitor, participam do processo de interpretação desses signos e narrativas que falam sobre a preservação da identidade e da importância da conservação da memória histórica do passado.

O romance de Gonçalo M. Tavares, ao abordar a histórica do Holocausto através da ficção, quase um século após o final da Segunda Guerra Mundial, apresenta-se como um testemunho literário e assume-se, assim, como um discurso de memória e de resistência. A literatura, desse 
modo, possui um valor ético e humanista, que possibilita a abertura de um espaço de reflexão sobre os traumas do passado e sobre a necessidade de preservação da memória e da história como forma de evitar a repetição das barbáries do século XX no futuro.

\section{Referências}

ADORNO, Theodor W. Prismas: critica cultural e sociedade. Trad. Augustin Wernet e Jorge Mattos Brito de Almeida. São Paulo: Ática, 1998.

ARENDT, Hannah. Eichmann em Jerusalém: um relato sobre a banalidade do mal. Trad. José Rubens Siqueira. São Paulo: Companhia das Letras, 1999.

BENJAMIN, Walter. Experiência e pobreza. In: BENJAMIN, Walter. Magia e técnica, arte e politica: ensaios sobre literatura e história da cultura. Trad. Sergio Paulo Rouanet. São Paulo: Editora Brasiliense, 1987. p. 114-120.

CANDAU, Joel. Memória e identidade. Trad. Maria Leticia Ferreira. São Paulo: Contexto, 2018.

CYTRYNOWICZ, Roney. O silêncio do sobrevivente: diálogos e rupturas entre memória e história do Holocausto. In: SELIGMANN-SILVA, Márcio (org.). História, memória, literatura: o testemunho na Era das Catástrofes. Campinas: Editora da Unicamp, 2003. p. 123-138.

GAGNEBIN, Jeanne Marie. O rastro e a cicatriz: metáforas da memória. Pró-Posições, [S. l.], v. 13, n.3, p. 125-133, set./dez. 2002

GAGNEBIN, Jeanne Marie. Após Auschwitz. In: SELIGMANN-SILVA, Márcio (org.). História, memória, literatura: o testemunho na Era das Catástrofes. Campinas: Editora da Unicamp, 2003. p. 89-110.

GAGNEBIN, Jeanne Marie. Lembrar, escrever, esquecer. São Paulo: Ed. 34, 2006.

GINZBURG, Jaime. Autoritarismo e literatura: a história como trauma. Vidya, Santa Maria, v. 19, n. 33, p. 43-51, jan./jun. 2000.

HOBSBAWM, Eric. A era dos extremos: o breve século XX (1914-1991). Trad. Marcos Santarrita. São Paulo: Companhia das Letras, 1995.

JUDT, Tony. Pós-guerra: uma história da Europa desde 1945. Rio de Janeiro: Objetiva, 2008.

MARINHO, Raquel. Escrever tem de ser organicamente indispensável. Expresso. Lisboa, 10 fev. 2016. Disponivel em: https://expresso.pt/cultura/2016-02-10-Escrever-tem-de-ser-organicamente-indispensavel?utm_sour$\mathrm{ce}=$ site\&utm_medium=share\&utm_campaign=facebook\&fbclid=|wARoO2Bas-88NAOh4m1ZR52p40YgYUjJmLMFjrg1-L3XqghlHjUJEJPZklj4. Acesso em: 14 jun. 2020.

PETROV, Petar. Narrativas desconcertantes: Os "Livros pretos" de Gonçalo M. Tavares. Revista Letras Comvida, Universidade do Algarve, n. 3, p. 125-131, 2011.
SELIGMANN-SILVA, Márcio. História, memória, literatura: o testemunho na Era das Catástrofes. Campinas: Editora da Unicamp, 2003

STEINER, George. Linguagem e ficção: ensaios sobre a crise da palavra. Trad. Gilda Stuart e Felipe Rajabally. São Paulo: Companhia das Letras, 1988.

TAVARES, Gonçalo M. Uma menina está perdida no seu século à procura do pai. São Paulo: Companhia das Letras, 2015

\section{Leonardo von Pfeil Rommel}

Mestre em Literatura Comparada pela Universidade Federal de Pelotas (UFPEL), em Pelotas, RS, Brasil; doutorando em Estudos de Literatura pela Universidade Federal do Rio Grande do Sul (UFRGS), em Porto Alegre, RS, Brasil.

\section{Endereço de correspondência}

Leonardo von Pfeil Rommel

Universidade Federal do Rio Grande do Sul

Programa de Pós-Graduação em Letras

Av. Bento Gonçalves, 9500, Campus do Vale, Prédio 43221, sala 122

Caixa Postal 15002

Agronomia, 91501970

Porto Alegre, RS, Brasil 